\title{
HLA-I-Überexpression auf Inselzellen maßgeblich für Genese des Typ-1-Diabetes
}

Hintergrund und Fragestellung: Bei der Pathogenese des Typ1-Diabetes (T1D) spielt das Immunsystem eine Schlüsselrolle. T1D-assoziierte Antikörper gegen Inselprotein wie GADA, IA2A, IAA oder ZnT8A sind der Goldstandard für die Risikoabschätzung und wichtig für die Differenzialdiagnose. Der zellulären Immunantwort, T-Helfer- und T-zytotoxische-Lymphozyten, sowie den Makrophagen und dendritischen Zellen wird eine große Rolle bei der Zerstörung der Inseln zugesprochen. Dabei werden T-Helfer-Zellen über die Antigenpräsentation und HLA-Klasse-II-Antigen aktiviert, T-zytotoxische-Zellen können die Betazellen, wenn sie HLA Klasse I exprimieren und Beta-Zellantigen selbst präsentieren, direkt angreifen.

Mittlerweile ist die Beteiligung sowohl von T-Helfer-als auch T-zytotoxischen-Lymphozyten bei der Inselzerstörung gesichert. Unklar war bisher, ob HLA Klasse I auch von Betazellen (über-)exprimiert wird. Damit könnten humane Betazellen an ihrem eigenen Untergang bei Typ-1-Diabetes beteiligt sein. Eine Überexpression von HLA-Klasse-I-Antigenen wurde etwa vor 30 Jahren erstmals beschrieben, aber nicht weiter analysiert und als Artefakt interpretiert. Daher untersuchten die Autoren die HLA-Klasse-I-Expression mittels Protein- und RNA-Analyse bei drei Kohorten von Typ-1-Diabetikern.

Ziel war es zu evaluieren, ob die HLA-Klasse-I-Überexpression ein Artefakt ist und, falls sie es nicht ist, welche Faktoren sie auslösen.

\section{Originalie}

Richardson SJ, Rodriguez-Calvo $\mathrm{T}$, Gerling IC et al. Islet cell hyperexpression of HLA class I antigens: a defining feature in type 1 diabetes. Diabetologia. 2016 Nov;59(11):2448-58.
Material und Methoden: Pankreasproben von Typ1-Diabetikern mit residuellen insulinpositiven Inseln ( $\mathrm{n}$ = 26) aus dem Netzwerk für pankreatischen Organspender mit Diabetes (nPOD), aus der Diabetes Virus Detek- tions Studie (DiViD) und aus einer Sammlung von Pankreata neu diagnostizierter Typ-1-Diabetiker aus Großbritannien wurden mit Immunfärbung für HLA-Klasse-I-Isoformen, Signal Transducer und Aktivator von Transkription 1 (STAT1), NLR family CARD domain containing 5 (NLRC5) und Inselhormonen untersucht. Die RNA wurde aus den mit Laser-CaptureMikrodissektion isolierten Inseln aus den NPOD- und DiViDProben gewonnen und mit Genexpressions-Arrays analysiert.

Ergebnisse: Eine Überexpression von HLA Klasse I wurde bei den insulinhaltigen Inseln von Typ-1-Diabetikern in allen 3 Gewebesammlungen gefunden. Dies wurde mit RNA und Proteinanalysen bestätigt. Die Expression von $\beta 2$-Mikroglobulin (das als zweite Komponente für die Bildung funktionsfähigen HLA-Klasse-I-Komplexen nötig ist) wurde ebenfalls evaluiert. Sowohl die "klassischen“ HLA-Klasse-I-Isoformen (z.B. HLA$\mathrm{ABC}$ ) als auch die „nicht klassischen“ HLA-Moleküle, HLA-f, wurden von den insulinhaltigen Inseln überexprimiert. Die Überexpression korrelierte nicht mit detektierbarer Hochregulation des transkriptionellen Regulators NLRC5. Es zeigte sich aber eine starke Assoziation mit einer erhöhten STAT1Expression in allen 3 Kohorten.

Die Überexpression von HLA-Klasse-I zeigte sich bei insulinhaltigen Inseln von neu diagnostizierten Typ-1-Diabetikern und war auch bei vielen mit einer Diabetesdauer bis zu 11 Jahren nachweisbar, danach nahm sie ab.

Schlussfolgerungen: Die vorliegende Arbeit zeigt, dass die Überexpression von HLA der Klasse I auf Pankreasinseln ein wichtiger Bestandteil der Immunpathogenese bei Typ-1-Diabetes ist. Die Überexpression ist eng assoziiert mit einer erhöhten Expression von STAT1. Beide zusammen sind einzigartig bei Typ-1-Diabetes und tragen zur selektiven Suszeptibiliät für autoimmune Zerstörung bei.

\section{- Kommentar von Prof. Dr. med. Nanette Schloot \\ Hoffnung auf neue Therapien}

Die Daten aus der npod-Studie und ähnlichen Studien rollen die schon lange bekannte Insulitis und deren Begleitphänomene noch einmal neu auf und bringen aufgrund deutlich besserer und selektiver Methoden teils Bestätigungen, wie in der aktuellen Studie, aber auch neue Aspekte. Dazu gehört z.B. die Erkenntnis, dass auch viele Jahre nach der Diagnose eines Typ-1-Diabetes noch insulinhaltige Zellen da sind. Es bleibt zu hoffen, dass die neuen Erkenntnisse in neue Therapien umzusetzen sind. Denn schon lange versucht man, das Immunsystem so zu modulieren, dass der Prozess der Insulitis gestoppt wird und so die Betazellen geschützt werden.

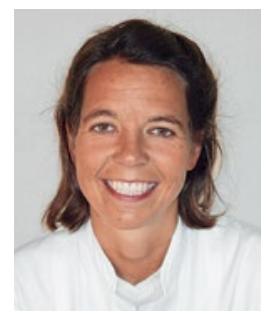

Prof. Dr. med. Nanette Schloot Deutsches Diabetes-Zentrum, Leibniz Zentrum für Diabetesforschung, Heinrich-Heine-Universität Düsseldorf Auf'm Hennekamp 65, 40225 Düsseldorf schloot@ddz.uni-duesseldorf.de 